\title{
A Vivência do Acompanhamento Pré-Natal Segundo Mulheres Assistidas na Rede Pública de Saúde
}

\author{
The Experience of Prenatal Care According to Women Assisted by Public Health System \\ La Vivencia del Acompañamiento Prenatal Según Mujeres Asistidas en la Red \\ Pública de Salud
}

\author{
Ana Caroline Dias da Silva \\ Renata Fabiana Pegoraro ${ }^{1}$ \\ Universidade Federal de Uberlândia
}

\begin{abstract}
Resumo
A atenção pré-natal consiste no acolhimento à mulher desde os primórdios da gestação. O objetivo deste estudo foi compreender a vivência do acompanhamento pré-natal na perspectiva de mulheres assistidas pelo Sistema Único de Saúde (SUS). Foram entrevistadas 11 mulheres, residentes no município de Uberlândia, Minas Gerais, em 2015. Foi utilizado um roteiro de entrevista semiestruturado composto por: (a) dados de caracterização da participante; e (b) questões norteadoras para investigar o transcorrer da gestação. As entrevistas foram transcritas na íntegra e submetidas à análise de conteúdo temática. Os resultados apontaram para uma valorização, por parte das entrevistadas, dos profissionais com postura acolhedora, favorecendo a percepção de um pré-natal de qualidade, identificado como aquele no qual eram fornecidas informações sobre os primeiros cuidados como bebê e com estratégias que permitiam espaço para reflexão sobre modificações físicas, psíquicas e hormonais que ocorrem com a mulher durante a gestação.

Palavras-chave: pré-natal, gravidez, Sistema Único de Saúde
\end{abstract}

\begin{abstract}
Prenatal care consists in the reception of the woman from the early stages of her pregnancy. The objective of this study is to understand the experience of prenatal care according to women assisted by Unified Health System (SUS). We have interviewed 11 women, living in the city of Uberlândia, Minas Gerais, in 2015, using a semi-structured interview script composed of: (a) characterization data of each participant; and (b) guiding questions to investigate the course of the pregnancy. The interviews were transcribed in full and submitted to the thematic content analysis. The results pointed that the welcoming attitude from the health team favored the perception of a high-quality prenatal care, which was recognized as a provider of useful information about baby care, and a space for reflecting on physical, psychic and hormonal woman changes that occur during the pregnancy.

Keywords: prenatal, pregnancy, Health Unic System
\end{abstract}

\section{Resumen}

La atención prenatal consiste en la acogida de la mujer desde el comienzo de la gestación. El objetivo de este estudio fue comprender la vivencia del acompañamiento prenatal en la perspectiva de mujeres asistidas por el Sistema Único de Salud (SUS). Se entrevistaron a 11 mujeres, residentes en el municipio de Uberlândia, Minas Gerais, en 2015. Se utilizó un guía de entrevista semiestructurado compuesto por: (a) datos de caracterización del participante; y (b) cuestiones orientadoras para investigar el transcurso de la gestación. Las entrevistas fueron transcritas en su totalidad y sometidas al análisis de contenido temático. Los resultados apuntaron a una valoración, por parte de las entrevistadas, de los profesionales con postura acogedora, favoreciendo la percepción de un prenatal de calidad. La importancia del prenatal fue reconocida por su capacidad de ofrecer informaciones acerca del cuidado con el bebé y destacó la brecha en relación a la información y espacio para reflexión sobre modificaciones físicas, psíquicas, hormonales que ocurren con la mujer durante la gestación. Palabras clave: prenatal, embarazo, Sistema Único de Salud.

\footnotetext{
${ }^{1}$ Endereço de contato: Av. Pará, 1720, BI. 2C, Sala 47, Bairro Umuarama, Uberlândia, MG, CEP 38405-320, Telefone: (34) 3218-2428. E-mail: renata.pegoraro@ufu.br
} 


\section{Introdução}

Este artigo aborda a vivência do acompanhamento pré-natal segundo mulheres assistidas em um equipamento público de saúde. No Brasil, o censo do Instituto Brasileiro de Geografia e Estatística referente ao ano de 2010 apontou que 62\% da população feminina com idade igual ou superior a 10 anos (51.621.903 pessoas) tiveram filhos, com concentração na faixa de 35 a 39 anos de idade (Instituto Brasileiro de Geografia e Estatística [IBGE], 2010). É recomendado pelo Ministério da Saúde que a assistência às gestantes seja realizada desde o princípio da gravidez, pois, assim, permite-se a efetivação de possíveis diagnósticos e a identificação de riscos associados à saúde materno-infantil (Ministério da Saúde, 2012). Apesar dessa recomendação, a pesquisa Nascer no Brasil: Inquérito Nacional sobre Parto e Nascimento, realizada nos anos de 2011 e 2012, concluiu que, apesar de o país possuir 99\% de cobertura da assistência pré-natal, a adequação desta ainda é incipiente, uma vez que $60 \%$ das mulheres grávidas deram início a tal assistência posteriormente à 12a semana gestacional, e aproximadamente $25 \%$ delas não compareceram a seis consultas ou mais no decorrer da gravidez, número mínimo exigido pelo Ministério da Saúde para o acompanhamento da gestante (Leal \& Gama, 2014).

Como estratégias institucionais para ampliar as garantias de segurança do bem-estar materno e infantil, o nascimento de uma criança saudável, o preparo da mulher para o parto e o aleitamento (Ministério da Saúde, 2012), o Ministério da Saúde lançou o Programa de Humanização do Parto e do Nascimento e a Rede Cegonha. Em junho de 2000, ao reconhecer a necessidade de estratégias que abarcassem a diminuição da taxa de mortalidade em território brasileiro, houve a instituição do Programa de Humanização no Pré-Natal e Nascimento (PHPN), visando à redução da morbimortalidade materna e infantil, à ampliação do acesso ao pré-natal, à qualificação de consultas e à promoção do vínculo entre a assistência ambulatorial e o parto (Ministério da Saúde, 2012). De acordo com esse modelo, o ato de dar à luz não pode ser tratado como uma doença ou uma patologia. Pelo contrário, deve ser compreendido como uma função fisiológica e natural, uma experiência excepcional para a mulher, seu(ua) parceiro(a), inclusa sua família (Ministério da Saúde, 2014). Já a Rede Cegonha deu continuidade à primeira estratégia ao fundamentar-se na abrangência do acesso e às melhorias na qualidade da assistência pré-natal, na garantia de um vínculo entre a mulher grávida e os serviços de referência que pregam o atendimento integral, no direito da gestante ao acompanhante de livre escolha durante o pré-natal, o parto, o puerpério, e, por fim, no acesso ao planejamento reprodutivo (Ministério da Saúde, 2014).

O Programa de Humanização no Pré-Natal e Nascimento (PHPN) afirma que é necessário conhecer o que as mulheres grávidas pensam sobre o pré-natal a fim de que a assistência seja proporcionada com qualidade (Ministério da Saúde, 2014). Ao longo do acompanhamento pré-natal, o Ministério da Saúde (2012) prevê que, no contato inicial, deva ser efetuada uma anamnese que aborde aspectos epidemiológicos, antecedentes familiares, pessoais, ginecológicos/obstétricos, que investigue a gestação em curso, além do exame físico, ginecológico e obstétrico. Nas consultas posteriores, a anamnese deve ser breve, abarcando aspectos do bem-estar da gestante e do feto. Além disso, o atendimento pré-natal deve envolver a criação de um espaço de acolhida que permita informar sobre a gestação, o puerpério e o parto, e permitir a expressão de demandas emocionais das gestantes, para o esclarecimento de 
dúvidas sobre mudanças relacionadas ao corpo e ao emocional, os receios e fantasias concernentes à gravidez e ao parto, dentre outros (Ministério da Saúde, 2012; Neto \& Taddei, 2000).

A partir das considerações anteriores, estabeleceram-se como problemas desta pesquisa as seguintes questões: Como as mulheres vivenciam o pré-natal? Quais informações recebem? Como percebem a atuação dos profissionais de saúde? Sentem-se acolhidas? Discutem o tipo de parto ao longo do pré-natal e tem influência sobre o tipo de parto realizado? A partir de tais problemas de pesquisa, o objetivo deste estudo foi compreender a vivência do acompanhamento pré-natal na perspectiva de mulheres assistidas em uma unidade de saúde da rede SUS.

\section{Metodologia}

A presente pesquisa foi desenvolvida a partir da perspectiva qualitativa e sob a forma de estudo descritivo. Nesse tipo de pesquisa, o interesse do pesquisador se assenta em apreender o sentido dos fenômenos investigados segundo a ótica dos participantes. Segundo Turato (2005), no campo da saúde, essa compreensão é fundamental para que as relações entre profissionais, pacientes, famílias e instituição se fortaleçam. Para Bosi (2012), o uso de pesquisas qualitativas no âmbito da avaliação de serviços em contextos de saúde coletiva abarca a investigação das construções intersubjetivas imersas em relações sociais e se beneficia de um olhar interdisciplinar.

Na presente pesquisa, participaram 11 mulheres, maiores de 18 anos, que tiveram ao menos um parto realizado em serviço da rede municipal de saúde de uma cidade do Estado de Minas Gerais, contatadas por meio de uma unidade básica de saúde (UBS). O número de entrevistas foi definido ao longo da coleta, utilizando-se o critério de saturação por amostragem (Fontanella, Ricas, \& Turato, 2008), ou seja, a partir do momento em que novas informações deixaram de surgir nas entrevistas, realiza-se mais uma entrevista e, ao se constatar a repetição das temáticas, a coleta é dada por encerrada. Segundo Turato (2005), em pesquisas qualitativas a amostragem é intencional, isto é, procuram-se participantes com experiência ou vivência prévia quanto ao tema investigado e o número da amostragem não é alto, já que não se busca a representatividade da população pela randomização dos sujeitos. Estudos qualitativos buscam compreender profundamente um tema a partir da ótica do investigado.

Foi utilizado um roteiro de entrevista semiestruturado, composto por duas partes, e elaborado para este estudo: (a) caracterização da participante (idade, número e idade dos fiIhos, partos realizados pelo SUS, se tinha companheiro, ocupação/profissão, religião, renda familiar e com quem residia); e (b) informações sobre o pré-natal e o parto, tais como o planejamento da gravidez, as vivências ao longo da gestação e a percepção sobre o atendimento pré-natal. Neste artigo, as vivências sobre o parto não foram analisadas, por não se tratar do foco do estudo, mas foram investigadas na entrevista por se tratar de um projeto de pesquisa de maior amplitude.

Com relação aos cuidados éticos, a pesquisa foi aprovada pelo Comitê de Ética em Pesquisa (CEP) com Seres Humanos da universidade à qual as pesquisadoras estão vinculadas (Parecer 922.584/2014), os gestores responsáveis pela UBS deram anuência formal antes do envio do 
projeto ao Comitê de Ética, bem como autorização para início da coleta, mediante apresentação do parecer de aprovação da pesquisa. Desse modo, a Resolução CNS 466/2012 sobre a realização de pesquisas com seres humanos (Ministério da Saúde, 2012) foi respeitada. Seguindo essa normativa, as participantes foram informadas sobre sua livre participação no estudo sobre a possibilidade de interromper a participação a qualquer momento e tiveram a preservação de identidade garantida. Foi assinado o Termo de Consentimento Livre e Esclarecido antes de cada entrevista e, para garantir o sigilo quanto à identidade frente ao serviço, a coleta foi efetuada na residência das participantes, com o deslocamento de uma das pesquisadoras até o local, em data e horários escolhidos pela participante. Logo após a realização das entrevistas, o material foi transcrito na íntegra, e, para preservar o sigilo quanto à identidade das participantes, no momento da apresentação dos resultados, utilizaram-se as siglas E1 para a primeira entrevistada, E2 para a segunda, e assim sucessivamente.

A UBS em que o convite às participantes foi feito funcionava das $7 \mathrm{~h}$ às $18 \mathrm{~h}$. Em janeiro de 2015, foi realizada uma primeira visita à UBS para realização de um pré-teste do instrumento de coleta, com a realização de uma entrevista-piloto. A coleta de dados transcorreu de março a julho de 2015. No momento do convite, as pesquisadoras apresentavam-se para as mulheres que aguardavam consulta na UBS, buscavam informações sobre número de fiIhos cujo pré-natal e parto foram realizados na rede SUS e averiguavam a disponibilidade da mulher para ceder a uma entrevista em sua residência, em dia e horário a ser definido pela entrevistada. Foram feitas doze visitas ao local, nos turnos matutino e vespertino, sendo que, no período da manhã, foi possível conseguir um número maior de colaboradoras.

Ao todo, catorze mulheres foram convidadas para participarem do estudo, mas três se recusaram, duas alegando falta de tempo, e uma não atendeu ao telefone nem se encontrava em sua residência no momento agendado para a entrevista. Todas as entrevistas foram feitas em uma única sessão, com duração média de 40 minutos, na residência das participantes.

As entrevistas foram transcritas na íntegra e submetidas à análise de conteúdo temática (Bardin, 2011). Ao longo da coleta efetuou-se a pré-análise, que envolve a avaliação das transcrições do material colhido, de forma a se determinar o ponto de saturação. A segunda etapa envolveu a exploração do material com a codificação inicial, agregando trechos das entrevistas por meio das unidades de sentidos. Por fim, foram estabelecidas as categorias de análise.

\section{Resultados}

\section{Caracterização das participantes}

A idade média das entrevistadas foi de 24 anos (mínimo de 18 e máximo de 36 anos), apenas uma não residia com companheiro, predominância de ensino médio completo $(F=6)$, seguido por ensino superior incompleto $(F=2)$ e completo $(F=1)$, fundamental completo $(F=1)$ e incompleto $(\mathrm{F}=1)$. Sete mulheres exerciam atividade remunerada (comerciante, cabelereira, depiladora, atendente e supervisora de telemarketing e auxiliar administrativo), duas eram donas de casa, uma era estudante, e uma estava desempregada. A renda familiar variou de $\mathrm{R} \$ 1500,00$ a $\mathrm{R} \$ 4000,00$. 


\section{Informações sobre o pré-natal e o parto}

O número de filhos variou de 1 a 3, quase todos nasceram em serviço de saúde da rede SUS, com exceção de um dos filhos das entrevistadas 3 e 4, nascidos pela rede particular. Com relação ao número de consultas de pré-natal referente ao último filho, este variou de 7 a 12 , sendo importante apontar que os partos normal $(F=6)$ e cesárea $(F=5)$ ocorreram em hospitais do próprio município.

\section{A vivência do acompanhamento pré-natal}

Nesta categoria foram agrupados os conteúdos referentes à vivência das participantes sobre a conduta dos profissionais que realizaram o atendimento pré-natal, a percepção sobre a estrutura física da unidade de saúde e o tempo para atendimento nessa unidade, a participação em grupos de gestantes e a (im)possibilidade de diálogo sobre o tipo de parto.

Ao longo do período pré-natal, as participantes perceberam o profissional médico da Unidade Básica de Saúde (UBS) que as acompanhava como o responsável pela prescrição de exames e medicamentos, realização de procedimentos clínicos e retirada de algumas dúvidas durante as consultas: ". . o o médico era mais assim [para perguntar] o quê que eu estou sentindo, os remédios que tem que tomar, tirar algumas dúvidas. Só" [E3]. Apesar dos adjetivos atribuídos a esse profissional ("calmo", "respeitoso", "atencioso") pelas entrevistadas, a maioria destacou sua insegurança frente à postura médica, pois, ao ouvirem sobre o desconforto físico ou dores, os médicos afirmavam que estava tudo normal: " . . falei que escorreu líquido na minha perna. Ele falou que não, que era xixi. Eu vi! Se ele não viu, como é que ele vai falar que não? Eu sei o que é xixi, o que é urina" [E9].

Em contrapartida, somente aspectos positivos foram atribuídos à equipe de enfermagem da UBS: os profissionais foram percebidos como receptivos, atenciosos, delicados, comunicativos, instruíam sobre os procedimentos para se marcar consultas e exames, e sempre observavam se as vacinas estavam atualizadas. Segundo as entrevistadas, a equipe de enfermagem prezava pela construção de vínculos com as pacientes, o que pode ser percebido pela atenção dada durante os atendimentos e pela liberdade para conversar, como no exemplo: ". . tratam a gente muito bem, com muito carinho, com muito amparo, fazem às vezes, até o que não está ao alcance delas, tanto as meninas da frente, quanto as meninas da... vacina, que são assim, maravilhosas" [E1].

Em um segundo tipo de unidade de saúde do município, responsável pelo pronto-atendimento da população e realização de exames mais complexos, os médicos e a equipe de enfermagem foram apontados como nervosos, estressados, desatenciosos e mal educados: ". . . acho que eles ficam muito nervosos, estressados, porque é muita gente [para atender]" [E3]. A principal diferença se assenta na relação estabelecida com esses profissionais: "Não tem carinho para conversar, não responde, não está nem aí, não tem dó, nem piedade. Eles tratam a gente como se a gente fosse qualquer pessoa" [E11]. É importante destacar que as participantes procuraram tal unidade não para a realização de todo o pré-natal, mas em situações específicas, a saber: nas férias dos médicos que as acompanhavam na UBS, quando necessitaram de alguma intervenção ou realização de exames de maior complexidade e a fim de serem encaminhadas ao local de parto. 
No que tange à estrutura física, as entrevistadas salientaram que as salas da UBS onde as consultas médicas ocorriam eram limpas, mas, se fossem mais organizadas, poderiam trazer maior tranquilidade às pacientes, melhorando, inclusive, a percepção sobre a higiene do local:

... por mais que o ambiente é limpo, mas sempre tem umas coisas assim que fica meio a desejar. ... a sala não era bem organizada, era uma bagunça e às vezes, poderia meIhorar a logística também, tanto para o médico quanto para os pacientes e por questão de aparência também, pra trazer mais tranquilidade, uma coisa mais bem feita [E10].

Apesar disso, destaca-se a falta e/ou inadequação de móveis e outros itens necessários ao atendimento:

. . muitas vezes, você chegava lá, eles estavam escrevendo em cima da pia, por falta de uma mesa. Não que seja culpa dos profissionais, mas eu acho que isso é problema do Estado, porque não favorece, não fornece um local adequado, muitas vezes então, você está deitado, não tem um lençol para você colocar [E1].

Pontos negativos com relação ao tempo para o atendimento também foram destacados. O primeiro foi a divergência na forma de contagem das semanas gestacionais entre os médicos da UBS e da unidade de pronto atendimento: ". . . você vai aqui [na UBS], eles fazem uma conta, você vai lá, dependendo do médico é outra, mas lá, sempre a conta da médica lá [da UAI], ... eu estava uma semana a menos ..." [E9].

O segundo ponto foi a troca do médico que acompanhava a paciente em virtude de cobertura de férias, gerando insegurança e insatisfação por ser atendida por um médico por quem não se tinha empatia e na demora em conseguir consultas com outro profissional. ". . . Aí, para piorar, em agosto, ele saiu de férias... Em agosto, eu estava entrando no nono mês. Fiquei louca! Falei assim: Como assim você vai sair de férias e vai me deixar sozinha?!" [E6]. Outro exemplo: "Fiquei um mês e vinte e cinco dias sem consulta. Eu já estava com sete meses" [E7].

O terceiro ponto negativo refere-se ao horário das consultas. No caso da UBS, as consultas eram marcadas no mesmo horário para todas as gestantes e o atendimento ocorria por ordem de chegada: ". . . a questão de hora marcada era meio complicada, porque ... era por ordem de chegada, estava marcado 7 hs, mas você ia ser atendida 10hs, porque era muita gestante, que marca no mesmo dia ..." [E10].

Isso gerou a impressão de que o médico acelerava os atendimentos, não existindo espaço suficiente para conversar e sanar dúvidas. Já na unidade de pronto atendimento, a insatisfação com a demora foi mais acentuada: "A [unidade de pronto atendimento] é a pior ...., eles demoram 'vinte anos' para te atender. Vou te falar a verdade, é um horror. Você entra de manhã e sai de noite" [E2].

O espaço da UBS foi descrito como mais organizado e menos tumultuado, se comparado à unidade de pronto atendimento, responsável por um maior número de atendimentos/dia. A maior organização da UBS do ponto de vista físico foi relacionada à forma como os profissionais lidam com as pacientes, isto é, com mais calma e tranquilidade. "Na [UBS], como não é tão bagunçado, tão tumultuado igual na [unidade de pronto atendimento], eu acho que eles [profissionais] ficam mais calmos também, eles tratam todo mundo bem" [E3]. 
As diferentes experiências de atendimento - em uma UBS e em uma unidade de pronto atendimento - apontam duas visões diferentes sobre os serviços da rede SUS. Uma delas aponta para baixas expectativas em relação aos profissionais do SUS, relacionando-se à unidade de pronto atendimento e o grande volume de usuários que nela circula: "Mas rede pública, você não pode esperar muito de um profissional, até porque são milhares de mulheres que eles vão atender e não tem aquela coisa toda, aquela preocupação assim... Sabe?! De te deixar bem confiável?! [sic]" [E6].

A segunda visão destaca boas surpresas com relação aos atendimentos do pré-natal efetuados pela UBS, trazendo à tona a ideia de um SUS que impressiona por ser eficiente como uma clínica particular [E2], diferente da expectativa criada pelo contato com as informações que circulam na mídia sobre o serviço público de saúde: "Em vista de tudo o que você escuta, né?! Eu acho que o meu [pré-natal] foi tranquilo" [E7]. A forma como os atendimentos transcorreram, diferente da expectativa inicial que algumas mulheres tinham, levou a imaginarem se foi sorte de sua parte receber tal atenção: "Eu não tenho nada pra queixar não. Eu achei que foi muito bom. Às vezes, é porque eu tive sorte (risos). Mas foi bom, a equipe médica que me atendeu foi boa" [E1].

Ao longo do pré-natal, as mulheres entrevistadas participaram de atividades grupais desenvolvidas na UBS. Os chamados "grupos de gestantes" foram descritos como rodas de conversa, grupos ou palestras, coordenadas/ministradas pela equipe de Enfermagem. As entrevistadas relataram que estes constituíam espaço propício para a troca de experiências com mulheres mais experientes e para a retirada de dúvidas junto à enfermeira responsável e a mães multíparas: ". . . Tem mulheres que é a quarta gravidez, tem muita experiência, então, teve duas normal, duas cesáreas, então, o que elas podem também, elas esclarecem [dúvidas] ..." [E1]. Outro depoimento também destaca a importância do espaço grupal para maior confiança das primíparas: "Para os primeiros cuidados da criança, para eu sentir mais confiança. Porque ali a maioria das minhas dúvidas, outras gestantes também tinham. Principalmente em relação ao parto, que é a coisa que você tem mais medo" [E6].

É importante apontar que todas as gestantes afirmaram que o grupo as ajudou bastante no cuidado com a criança, oferecendo-Ihes confiança: " $E$ eu aprendi muito nessas palestras. Porque, quando é o primeiro filho, a gente tem muita dúvida. E ajuda... . . ." [E7]. Nas reuniões grupais, foram abordados temas como: tipos de parto, parto humanizado, amamentação, armazenamento do leite materno, como proceder quando a criança nasce prematura, procedimentos para dar banho e cuidar do umbigo do bebê, doenças típicas do recém-nascido, como icterícia e cólica, informações sobre o tampão do útero e como agir com o companheiro quando a criança nasce, dentre outros. Além disso, as mulheres afirmaram que os profissionais coordenadores das rodas de conversa eram muito atenciosos e usavam recursos lúdicos a fim de ilustrar o assunto discutido, o que fazia com que a participação nas reuniões educativas fosse mais proveitosa:

Na época tinha os cursos das gestantes que ensinava [cuidados com o bebê] a gente. Toda vez que eu tive pré-natal, tinha os cursos. Aí, enquanto a gente aguardava a consulta, as enfermeiras vinham, davam atenção, pegavam a bonequinha, ensinava pra gente. O pessoal foi muito atencioso [E5]. 
Em contrapartida, alguns aspectos negativos foram atribuídos aos grupos de gestante, tais como: falta de material didático, por exemplo, uma cartilha com as orientações dadas verbalmente, e a falta de mais atividades de caráter prático: "Teve [instruções para os primeiros cuidados com o bebê], mas não teve nada prático, foi só mais teoria. Eles colocavam cartazes... Prática mesmo, não teve, não" [E8]. Outro exemplo segue abaixo:

... Vem o problema também do material, que eu acho que o Estado não fornece para nós, que é uma cartilha explicando, tem uma cartilha que você recebe quando você pega seu cartão de gestante, sabe? Só que nessas reuniões não tem um material didático [E1].

As participantes destacaram como empecilhos quanto ao comparecimento às reuniões educativas o horário em que estas ocorriam (muito cedo e, às vezes, horário oposto ao da consulta médica), não ter tempo para participar e pensar que já possuía noção do conteúdo discutido nas reuniões: "Por causa do horário, acordar cedo é complicado [participar]. Sete horas da manhã que começava" [E3]. Outro depoimento destaca:

. . Eram em dias da semana fixo e eu sei que a consulta não era no mesmo dia . . . E também por achar, e essa já é a terceira [gestação], então já estou preparada, mas é ignorância, porque cada dia é uma coisa diferente [E9].

Ainda que tivessem recebido informações sobre o tipo de parto nos grupos de gestantes, as entrevistadas afirmaram que, durante as consultas médicas, não houve espaço para discussão sobre tipo de parto recomendável para cada caso, apenas tiraram dúvidas sobre as vantagens e desvantagens de cada um:

. . teve falando sobre os tipos de parto [durante o pré-natal], o parto normal e o parto cesárea, mas não teve falando assim: 'Ó, o indicado para você é esse, o indicado para você é esse, a chance de você ter esse é tanto e a chance de você ter o outro é tanto'. Não teve isso, sempre foi uma incógnita, sempre foi ... [E1].

Os relatos indicaram que não é possibilitada às gestantes a escolha do parto, bem como do médico que o fará: "Na época, ela [médica] atendia lá na [unidade de pronto atendimento]. E aí, ela falou assim: Eu não posso te garantir nada [tipo de parto que a gestante faria]. Também não te garanto que será [o parto] comigo" [E4].

Além do mais, foi evidenciado que a rede SUS preza o parto normal em detrimento à cesariana, o que gera medo e insegurança em algumas mulheres:

... mas quem conhece um pouco do sistema, sabe que a primeira opção é o parto normal. ... eles vão te deixar lá dois, três dias em trabalho de parto, na hora que tiver no seu limite, que vê que você não vai ter normal, aí eles vão te fazer uma cesárea, caso contrário, não vai ser [E1].

... meu maior medo mesmo foi o parto e na rede pública, ..., pesquisei pra saber por que eles preferem parto normal, aí eu vi que tem uma lei que tem que ter não sei quantos partos por ano cesárea, por causa da anestesia. A anestesia dá problema na coluna e tudo mais, e eu fui entendendo mais. Aí assim, até que eu fiquei meio que conformada, mas mesmo assim, não justifica algumas atitudes que eles tomam, [como] deixar uma mulher até 42 semanas, assim, vendo que não vai dar parto normal e não fazer uma cesárea [E10]. 


\section{Discussão}

A faixa etária das entrevistadas (18 a 36 anos) é semelhante à idade relatada em outras pesquisas nacionais que discutiram o pré-natal em alguns munícipios brasileiros (Costa, Vila, Rodrigues, Martins \& Pinho, 2013; Piccinni, Carvalho, Ourique, \& Lopes, 2012). As entrevistadas fizeram entre sete e doze consultas durante suas gestações, ou seja, uma quantidade superior àquela preconizada pelo Ministério da Saúde (2012) que prevê, minimamente, seis consultas a serem concretizadas a fim de uma adequada assistência pré-natal. Ao analisar o nível de escolaridade e o número de consultas de pré-natal realizadas, percebeu-se que o grau de instrução das mães não interferiu no número de consultas. A literatura consultada demonstrava que gestantes com baixa escolaridade (menos de nove anos) realizavam uma quantidade inferior de consultas de pré-natal. Porém, em nosso estudo, era esperado um maior número de consultas, independente do grau de escolaridade, uma vez que o convite para a participação da pesquisa ocorreu na unidade de saúde, anteriormente ou posteriormente às consultas de pré-natal, ou seja, as mulheres eram assíduas em relação às essas consultas.

No que se refere aos médicos e à equipe de enfermagem, quando avaliados positivamente, foram vistos pelas entrevistadas como atenciosos, receptivos e comunicativos. É interessante apontar que as mulheres demonstraram mais liberdade para expressar suas preocupações e sentimentos com os enfermeiros e técnicos em enfermagem. Já o profissional de medicina foi relacionado a uma função mais técnica, ou seja, prescrição de exames laboratoriais, realização de procedimentos clínicos e sanar dúvidas que a equipe de enfermagem não conseguiu responder. A partir das entrevistas, podemos destacar que a equipe de enfermagem que acompanhou o pré-natal, segundo a ótica das entrevistadas, não direcionava seus procedimentos apenas aos aspectos biologicistas, prezando a construção de vínculos com as gestantes e tornando-se fonte de apoio emocional. Piccinini et al. (2012) sugerem que todos os profissionais da saúde devem superar o biologicismo e cuidar da saúde da mulher e da criança de modo integral.

Os profissionais da saúde, quando avaliados negativamente, foram descritos como possuidores de pouca sensibilidade ao lidar com a saúde da gestante e do bebê, além de indisponíveis para o estabelecimento de diálogos e para o esclarecimento de dúvidas, assim como evidenciado por Piccinini et al. (2012). A literatura assinala ser essencial que os profissionais da saúde estejam abertos às conversas dialógicas (Bonilha, Schmalfuss, Moretto, Lipinski, \& Porciuncula, 2010; Duarte \& Andrade, 2008; Landerdahl, Ressel, Martins, Cabral, \& Gonçalves, 2007). Ademais, os autores elencados destacaram a importância de a gestante, durante o pré-natal, perceber-se livre e à vontade para pedir informações aos profissionais de saúde, ou seja, uma interação com doses de confiabilidade se faz necessária.

As participantes apontaram questões relacionadas ao espaço físico, destacando que, em geral, os ambientes das unidades de saúde eram limpos, todavia poderiam ser mais organizados, uma vez que isso Ihes traria mais tranquilidade. O Ministério da Saúde (2010) discute, através do conceito de ambiência, o tratamento oferecido ao espaço físico entendido como um ambiente social, profissional e de relacionamentos interpessoais no campo da saúde. O conceito de ambiência envolve três aspectos: (a) a confortabilidade do ambiente, a qual foca a privacidade e a individualidade dos sujeitos nele dispostos, exaltando elementos 
ambientais que interatuam com as pessoas, tais como cor, cheiro, som, iluminação e morfologia, garantindo, portanto, a comodidade dos usuários; (b) a produção de subjetividades possibilitada através da ação e da reflexão acerca dos processos de trabalho; e (c) a otimização de recursos, o atendimento humanizado, acolhedor e resolutivo.

No presente estudo, é interessante assinalar que a maior parte das reclamações não foi relacionada aos móveis ou à confortabilidade da estrutura física disponível, porém à forma como os profissionais lidavam com as pacientes. Na UBS, as participantes apontaram que a interação acontecia com mais calma e de forma mais acolhedora, se comparada à unidade de pronto atendimento. Além do mais, as entrevistadas salientaram que, na UBS, as consultas de pré-natal eram agendadas para todas as gestantes no mesmo horário, se dando, portanto, através da ordem de chegada, ou seja, elas ficavam bastante tempo aguardando o atendimento e, na percepção das mulheres, a duração da consulta era encurtada por conta da alta demanda. Pode-se inferir, com isso, que o atendimento humanizado e a atenção acoIherada foram prejudicados.

Os relatos apontaram que as atividades educativas desenvolvidas por meio dos grupos de gestante foram direcionadas para discussões acerca dos cuidados com o bebê, não abarcando as modificações físicas e psíquicas que ocorrem com a mulher, nem a figura paterna. Percebe-se, a partir dos depoimentos, uma lacuna nos temas elencados para serem abordados junto às gestantes, assim como foi observado no estudo de Silva et al. (2012). Zanatta e Pereira (2015) os quais apontaram que as gestantes sentem maior sensibilidade emocional e choram frequentemente. É necessário que o serviço público se sensibilize diante desse quadro, pois a gravidez por si só já é uma vivência psiquicamente complexa (Gomes, Marin, Piccinini, \& Lopes, 2015) e, por isso, é preciso cuidar da saúde da mulher de uma maneira integral.

Além disso, segundo o Ministério da Saúde (2001), as atividades educativas possuem a finalidade de oferecer às gestantes orientações gerais sobre a gestação e o parto e, por isso, devem abordar os seguintes tópicos: modificações fisiológicas e emocionais, cuidados com o bebê, amamentação e planejamento familiar. Ademais, é preciso envolver o pai, respeitar a cultura e o saber popular, e promover a participação ativa da parturiente no parto. No presente estudo, a participação do pai em grupos educativos não foi destacada. Souza, Roecker e Marcon (2011) complementam que o grupo de gestantes deve realizar discussões sobre hábitos alimentícios, prática de exercícios físicos, conhecimentos teóricos mediante ao processo global da gravidez, e tais orientações foram passadas ao longo dos encontros, conforme apontado pelas entrevistadas.

As participantes afirmaram que o grupo de gestantes favoreceu a interação entre elas, uma vez que compartilharam experiências, conhecimentos e vivenciaram experiências similares. Isso é evidenciado por Souza, Roecker e Marcon (2011) e pelo Ministério da Saúde (2001) que compactuam com a visão de o grupo de gestantes contribuir para a construção de saberes coesos e promotores de saúde.

A orientação para realizar o pré-natal em uma UBS próxima às suas residências despertou nas entrevistadas a sensação de serem obrigadas a tal, além disso, implicou a sensação de perder o poder de escolha do médico que as acompanhariam durante o período gestacional. A proximidade geográfica da residência da mulher grávida é apontada pelo Programa de 
Humanização no Pré-Natal e Nascimento (PHPN) como critério exclusivo de referência para o local de realização do pré-natal. Segundo Almeida e Tanaka (2009), isso pode constituir-se em um fator de insatisfação no que se refere ao atendimento do pré-natal, tal qual destacado por parte das entrevistadas da presente pesquisa. Por outro lado, Silva, et al. (2012) ressalvaram que a proximidade da moradia em relação à USB, de acordo com as participantes de seu estudo, consistiu em um fator favorecedor da adesão de mulheres ao pré-natal.

Landerdahl et al. (2007) salientaram que, para a gestante, algo extremamente relevante, é que o pré-natal seja realizado pelo mesmo profissional durante todo o processo. De acordo com as entrevistadas no presente estudo, quando isso não ocorreu, elas se sentiram ansiosas, gerando uma situação de desconforto.

A partir dos relatos, identificou-se que está presente no imaginário das entrevistadas a ideia de um SUS que oferece serviços de má qualidade, se comparado à rede particular. Ao perceberem atendimento de boa qualidade, o SUS era comparado aos serviços particulares, assim como também foi revelado pela pesquisa de Piccinini et al. (2012). As entrevistadas em nosso estudo afirmaram que explicações sobre os tipos de parto foram fornecidas durante o pré-natal, porém os médicos não discutiram o parto com elas, as quais não tiveram escolha no que se refere ao parto que fariam, nem ao médico que realizaria o procedimento. Tais aspectos foram corroborados pela pesquisa de Piccinini et al. (2012) que evidenciaram também a relevância da transmissão de informações acerca dos procedimentos de parto e puerpério. O Ministério da Saúde (2010) alega que é função do pré-natal preparar a mulher para o parto. Afirma ainda que a escolha do tipo de parto é uma decisão do médico, porém com a participação ativa da gestante, uma vez que o parto apresenta uma série de implicações, dentre elas, riscos e benefícios, dependendo de cada conjuntura, tempo de realização, complicações e reverberações futuras. A participação ativa das mulheres entrevistadas na escolha do parto não foi observada.

Além do mais, foi evidenciado que a rede SUS preza pelo parto normal em detrimento da cesariana. A Organização Mundial de Saúde (2015) aponta que esta é uma intervenção efetiva que visa salvar a vida de mulheres e crianças, porém somente quando recomendada por motivos médicos, ou seja, a cesárea deve ser realizada apenas em casos nos quais haja necessidade, pois pode ocasionar complicações expressivas e, às vezes, permanentes, bem como sequelas ou morte.

\section{Considerações Finais}

O objetivo geral desta pesquisa foi compreender a vivência do acompanhamento pré-natal na perspectiva de mulheres assistidas pelo Sistema Único de Saúde (SUS), e pode-se apontar que ele foi atingido. Pode-se perceber que houve uma valorização, por parte das entrevistadas, dos profissionais que as acolheram e ouviram, que estabeleceram vínculo com estas durante o acompanhamento pré-natal, o que favoreceu a percepção de boa qualidade no atendimento. Faz-se necessário que todos os profissionais envolvidos tenham a mesma postura acolhedora e que permitam/estimulem a autonomia das mulheres para que elas vivenciem ativamente o pré-natal e a decisão sobre o tipo de parto que realizarão. As participantes reconheceram a importância do acompanhamento grupal nessa etapa de suas vidas, uma vez que este ofereceu informações acerca de seus bebês e de como cuidar deles, porém não 
foram abarcadas as modificações físicas, psíquicas, hormonais que ocorrem com a mulher durante seus períodos gestacionais, não a preparando para o parto, nem para a maternidade. Foi entregue cópia do relatório da pesquisa e efetuada uma devolutiva do estudo a um gestor de saúde do município, o que se considera como compromisso das pesquisadoras para com as participantes, na medida em que foi possível dar visibilidade à compreensão destas sobre o acompanhamento pré-natal. Ressalta-se como limitação do estudo o fato de que as entrevistadas foram convidadas a partir de uma única unidade de saúde. Logo, os relatos aqui registrados e analisados expressam as concepções de mulheres atendidas por essa unidade, sem a pretensão de ser representativo de todo o município. No entanto cumpre um dos intentos da pesquisa qualitativa de compreender o ponto de vista do participante do estudo sobre o fenômeno vivenciado e nos coloca, como reflexão necessária, a importância da relação profissional-paciente no âmbito do Sistema Único de Saúde como promotora de saúde.

\section{Referências}

Almeida, C. A. L. \& Tanaka, O. Y. (2009). Perspectiva das mulheres na avaliação do Programa de Humanização do Pré-Natal e Nascimento. Revista Saúde Pública, 43(1), 98-104. Disponível em http://www.scielo.br/pdf/rsp/v43n1/7296.pdf

Bardin, L. (2011). Análise de conteúdo. São Paulo: Edições 70.

Bonilha, A. L. de L., Schmalfuss, J. M., Moretto, V. L., Lipinski, J. M., \& Porciuncula, M. B. (2010). Capacitação participativa de pré-natalistas para a promoção do aleitamento materno. Revista Brasileira de Enfermagem, 63(5), 811-816. doi:10.1590/S0034-71672010000500019

Bosi, M. L. M. (2012). Pesquisa qualitativa em saúde coletiva: Panorama e desafios. Ciência \& Saúde Coletiva, 17(3), 575-586. Disponível em http://www.scielo.br/pdf/csc/v17n3/ v17n3a02

Costa, C. S. C., Vila, V. S. C., Rodrigues, F. M., Martins, C. A., \& Pinho, L. M. O. (2013). Características do atendimento pré-natal na rede básica de saúde. Revista Eletrônica de Enfermagem, 15(2), 516-522. Disponível em https://www.revistas.ufg.br/fen/article/view/15635

Duarte, S. J. H., \& Andrade, S. M. O. (2008). O significado do pré-natal para mulheres grávidas: Uma experiência no município de Campo Grande, Brasil. Saúde e Sociedade, 17(2), 132139. doi:10.1590/S0104-12902008000200013

Fontanella, B. J. B., Ricas, J., \& Turato, E. R. (2008). Amostragem por saturação em pesquisas qualitativas em saúde: Contribuições teóricas. Cadernos de Saúde Pública, 24(1), 17-27. doi:10.1590/s0102-311X2008000100003

Gomes, A. G., Marin, A. H., Piccinini, C. A., \& Lopes, R. C. S. (2015). Expectativas e sentimentos de gestantes solteiras em relação aos seus bebês. Temas em Psicologia, 23(2), 399-411. doi:10.9788/TP2015.2-12

Instituto Brasileiro de Geografia e Estatística. (2010). Nupcialidade, fecundidade e migração tabelas. Censo Demográfico. Rio de Janeiro: IBGE. Disponível em ftp.ibge.gov.br/Censos/ Censo_Demografico_2010/Nupcialidade_Fecundidade_Migracao/tab1_2.pdf

Landerdahl, M. C., Ressel, L. B., Martins, F. B., Cabral F. B., \& Gonçalves, M. O. (2007). A percepção de mulheres sobre atenção pré-natal em uma unidade básica de saúde. Revista de Enfermagem, 11(1), 105-111. Disponível em http://www.scielo.br/pdf/ean/ v11n1/v11n1a15 
Leal, M. C. \& Gama, S. G. N. (2014). Nascer no Brasil [Editorial]. Cadernos de Saúde Pública, 30(1). doi:10.1590/0102-311XED01S114

Ministério da Saúde. (2001). Parto, aborto e puerpério: Assistência humanizada à mulher.

Brasília: Ministério da Saúde. Disponível em http://bvsms.saude.gov.br/bvs/publicacoes/ cd04_13.pdf.

Ministério da Saúde. (2010). Ambiência. Brasília: Ministério da Saúde. Disponível em http:// bvsms.saude.gov.br/bvs/publicacoes/ambiencia_2ed.pdf.

Ministério da Saúde. (2012). Atenção ao pré-natal de baixo risco (Cadernos de Atenção Básica, 32). Brasília: Ministério da Saúde. Disponível em: http://bvsms.saude.gov.br/bvs/ publicacoes/cadernos_atencao_basica_32_prenatal.pdf

Ministério da Saúde. (2014). Humanização do parto e do nascimento. Brasília: Ministério da Saúde. Disponível em www.redehumanizasus.net/sites/default/files/caderno_ humanizasus_v4_humanizacao_parto.pdf.

Neto, B. H. \& Taddei, J. A. C. (2000). Mudança de conhecimento de gestante em aleitamento materno através de atividade educacional. Revista Paulista de Pediatria, 18(1), 7-14. Disponível em http://pesquisa.bvsalud.org/ses/resource/pt/lil-363110

Organização Mundial da Saúde. (2015). Declaração da OMS sobre Taxas de Cesáreas. Disponível em_http://apps.who.int/iris/bitstream/10665/161442/3/WHO_RHR_15.02_por.pdf

Piccinini, C. A., Carvalho, F. T. de, Ourique, L. R., \& Lopes, R. S. (2012). Percepções e sentimentos de gestantes sobre o pré-natal. Psicologia: Teoria e Pesquisa, 28(1), 27-33. doi:10.1590/ S0102-37722012000100004

Silva, R. M. da, Costa, M. S., Matsue, R. Y., Sousa, G. S. de, Catrib, A. M. F. , Vieira, L. J. E. (2012). Cartografia do cuidado na saúde da gestante. Ciência \& Saúde Coletiva, 17(3), 635-642. Disponível em https://www.scielosp.org/pdf/csc/v17n3/v17n3a09.pdf

Souza, V. B., Roecker, S., \& Marcon, S. S. (2011). Ações educativas durante a assistência prénatal: Percepção de gestantes atendidas na rede básica de Maringá-PR. Revista Eletrônica de Enfermagem, 13(2), 199-210. Disponível em: www.fen.ufg.br/revista/v13/n2/v13n2a06.htm

Turato, E. R. (2005). Métodos qualitativos e quantitativos na área da saúde: Definições, diferenças e seus objetos de pesquisa. Revista de Saúde Pública, 39(3), 507-514. doi:10.1590/S0034-8910200500030002

Zanatta, E., \& Pereira, C. R. R. (2015). Ela enxerga em ti o mundo: A experiência da maternidade pela primeira vez. Temas em Psicologia, 23(4), 959-972. doi:10.9788/TP2015.4-12

Recebido: $11 / 12 / 2017$

última revisão: 28/03/2018

Aceite final: $12 / 06 / 2018$

\section{Sobre as autoras:}

Ana Caroline Dias da Silva- Psicóloga e Mestranda do Instituto de Psicologia da Universidade Federal de Uberlândia, pela UFU. E-mail: diassilvacarol@hotmail.com.

Renata Fabiana Pegoraro- Doutora e Mestre em Psicologia pela USP/Ribeirão, Especialista em Saúde Coletiva pela UFSCar, Psicóloga pela USP/Ribeirão. Professora Adjunta do Instituto de Psicologia da Universidade federal de Uberlândia (UFU). Docente do Instituto de Psicologia da UFU. E-mail: renata.pegoraro@ufu.br 
